\title{
Acquired Activated Protein C Resistance, Thrombophilia and Adverse Pregnancy Outcomes: A Study Performed in an Irish Cohort of Pregnant Women
}

\author{
Sara Sedano-Balbás, ${ }^{1}$ Mark Lyons, ${ }^{2}$ Brendan Cleary, ${ }^{2}$ Margaret Murray, ${ }^{2}$ \\ Geraldine Gaffney, ${ }^{3}$ and Majella Maher ${ }^{1}$ \\ ${ }^{1}$ Molecular Diagnostics Research Group, National Centre for Biomedical Engineering Science, \\ National University of Ireland, Galway, Ireland \\ ${ }^{2}$ Department of Haematology, University College Hospital, Galway, Ireland \\ ${ }^{3}$ Department of Obstetrics \& Gynaecology, University College Hospital, Galway, Ireland
}

Correspondence should be addressed to Sara Sedano-Balbás, sara.sedano@nuigalway.ie

Received 16 December 2010; Revised 29 April 2011; Accepted 31 May 2011

Academic Editor: Sinuhe Hahn

Copyright (C) 2011 Sara Sedano-Balbás et al. This is an open access article distributed under the Creative Commons Attribution License, which permits unrestricted use, distribution, and reproduction in any medium, provided the original work is properly cited.

The combination of thrombophilia and pregnancy increases the risk of thrombosis and the potential for adverse outcomes during pregnancy. The most significant common inherited risk factor for thrombophilia is activated protein C resistance (APCR), a poor anticoagulant response of APC in haemostasis, which is mainly caused by an inherited single-nucleotide polymorphism (SNP), factor V G1691A (FV Leiden) (FVL), referred as inherited APCR. Changes in the levels of coagulation factors: FV, FVIII, and FIX, and anticoagulant factors: protein S (PS) and protein C (PC) can alter APC function causing acquired APCR. Prothrombin G20210A and methylenetetrahydrofolate reductase (MTHFR) C677T are prothrombotic SNPs which in association with APCR can also increase the risk of thrombosis amongst Caucasians. In this study, a correlation between an acquired APCR phenotype and increased levels of factors V, VIII, and IX was demonstrated. Thrombophilic mutations amongst our acquired APCR pregnant women cohort are relatively common but do not appear to exert a severe undue adverse effect on pregnancy.

\section{Introduction}

Pregnancy increases the risk of thrombosis. APCR phenotype has been associated with venous thromboembolism (VTE), the primary cause of maternal death in developed countries [1-3].

In normal conditions, APC inactivates the coagulant protein active $\mathrm{FV}(\mathrm{a})$ by cleaving in an ordered sequence specific sites of $\mathrm{FV}(\mathrm{a})$. The first cleavage site is Arginine (Arg) 506, and the second is (Arg) 306 followed by (Arg) 679 [4]. Mutations in the FV gene have been related to APCR. FVL is reported in about $90 \%$ of patients with APCR in the general population [5-7]. Other SNPs in the factor $\mathrm{V}$ gene which may contribute to inherited APCR either independently or found in association with the FVL mutation include Cambridge $\mathrm{Arg}^{306}$, Hong Kong, $\mathrm{Arg}^{306}$, the $\mathrm{Arg}^{679}$, and the haplotype (H) R2 and R3 polymorphisms. However, reports on the contribution of these mutations to the APCR phenotype are conflicting [7-10].

The pathophysiology underlying APCR not caused by the FVL mutation is still not completely understood. In different studies, it has been suggested that acquired factors might be the cause of APCR in the absence of FV Leiden [11, 12]. A number of coagulation factors can affect the activated partial thromboplastin time (aPTT). Previous literature suggested a possible positive correlation between levels of factors V, VIII and IX and acquired APCR [13]. Protein S and protein C, levels can (or may) affect acquired APCR, but their influence on the resistance seems to be still within the range of normal levels [14]. 
Other known SNPs associated with thrombophilia and adverse outcomes during pregnancy are prothrombin G20210A and MTHFR C677T [15-17].

Prothrombin G20210A is associated with an increase in the level of prothrombin protein (FII) in plasma and a resulting 3-fold increase in thrombotic events. The prothrombin G20210A mutation seems to increase the risk of thrombosis in pregnant women by approximately tenfold [18] with the risk of developing obstetric complications increased by fourfold [16].

The MTHFR C677T has been associated with obstetric complications and with birth defects $[19,20]$.

In a previous study in this laboratory, we identified known and novel SNPs in a small number of subjects with APCR determined using the modified Coatest test which did not have the FVL mutation [21].

The main objectives of this study were to (1) determine and compare the levels of factors V, VIII, and IX in the acquired APCR, inherited APCR, and APCR-negative groups, (2) compare the frequency of adverse outcomes in the APCR-positive (acquired and inherited) and APCRnegative groups, and (3) determine the frequency of adverse pregnancy outcomes, associated with thrombophilic mutations other than FVL mutation in our study cohort $(n=$ 907). The adverse pregnancy outcomes observed in this study included (previous) recurrent early pregnancy loss (REPL), preeclampsia (PET), and intrauterine growth restriction (IUGR). Pregnancy induced hypertension (PIH), (IUFD) intrauterine fetal dead, and low birth weight (LBW).

\section{Materials and Methods}

2.1. Subjects. Ethical approval for the study was obtained from the Research Ethics Committee, and written consent for samples to be collected was obtained from the 907 pregnant women included in this study who attended for routine outpatient gestational screening at the antenatal clinic at University College Hospital, Galway, (UCHG). Table 1 details the demographics of the study subjects.

Blood samples (Lithium Heparin and EDTA) were collected from subjects between the 16th to 24th weeks of gestation. In this second trimester of pregnancy, little or almost no variation on the coagulation factors has been shown which is appropriate for the assessment of APC status [22]. Testing of APC status before or from 8 to 12 weeks after pregnancy or more frequently during pregnancy would have determined a more accurate stable APC ratio; this is a limitation of the current study. The laboratory analysis of poor anticoagulant response to APC is based on an activated partial thromboplastin time (aPTT) assay. A reduced ratio reflects the reduced rate of inactivation. The cutoff ratio used to determine positive APCR for this study was a value of less than or equal to 2.1 seconds (s). This value was determined by the haematology department and it is in clinical use at UCHG. The cut-off ratio used to determine APCR can vary in sensitivity and specificity depending on the methodology, equipment, and technology used in different laboratories.
2.2. APC Status by Classic Coatest Test in Order to Identify Acquired APCR Samples. Blood samples were centrifuged at $4,000 \mathrm{rpm}$ for $5 \mathrm{~min}$, and aliquots of platelet-poor plasma were frozen at $-80^{\circ} \mathrm{C}$ until the assay took place. Plasma was incubated with an equal volume of aPTT reagent for $5 \mathrm{~min}$ at $37^{\circ} \mathrm{C}$. Clotting was initiated by the addition of $\mathrm{CaCl}_{2}$, and clotting times were expressed as a ratio of clotting time in the presence of APC divided by the clotting time in the absence of APC.

2.3. APC Status by Modified Coatest Test in Order to Identify Inherited APCR Samples. Blood samples were first diluted 1 in 5 with factor $\mathrm{V}$-deficient plasma that contains a heparin neutralizer, and then it was assayed as described for the APCR classic Coatest test. The addition of the factor Vdeficient plasma corrects for deficiencies of other coagulation proteins, neutralises therapeutic concentrations of heparin, and eliminates the effect of some lupus inhibitors [23]. APCR in the presence of factor V-depleted plasma was assessed using the Coatest APCR-kit and factor V-depleted plasma (Chromogenix) [24].

2.4. DNA Extraction. DNA was extracted from blood samples for all APCR subjects $(n=140)$ and control samples (negative APCR $n=31$ ) using a modification of the CF(12)mPCR protocol by Ortho-Clinical Diagnostics, Amersham, UK. Spectrophotometric analysis of absorbance at $260 \mathrm{~nm}$ was performed in a Helios $\alpha$ spectrophotometer (Unicam Ltd., England) for each DNA sample, and the average yield for DNA was determined to be $30 \mathrm{ng} / \mu \mathrm{L}$.

2.5. Mutation Screening. PCR-restriction enzyme analysis (PCR-REA) was applied to identify G20210A in the FII gene, C677T in the MTHFR gene, and FVL, FV Cambridge, FV Hong Kong mutations, and Haplotype $(\mathrm{H}) \mathrm{R} 2$, allele in the FV gene using modifications of previously published methods [6, 25-29]. DNA probe hybridisation analysis and/or DNA sequencing was applied for $\operatorname{Arg}^{679}$ detection as described [21]. One hundred and forty APCR-positive subjects and 31 APCR-negative subjects were tested for all mutations. Our group of control subjects tested for thrombophilic mutations, $n=31$, was chosen randomly out of the 767 negative APCR subjects identified as normal with the APCR classic Coatest test. A mean of 2.59 and standard deviation of 0.2804 were identified for this negative APCR group of $n=767$ subjects. Conversely, a mean of 1.745 and standard deviation of 0.1104 were identified for the positive APCR (inherited plus acquired) $n=140$. The minimum value identified for negative APCR was 2.160 whereas for positive APCR was 1.490. The maximum negative APCR value identified was 3.030, whereas for positive APCR it was 2.060 seconds. Thrombophilic mutations are interfering with the coagulation equilibrium varying the aPTT time related to $\mathrm{APC}$ ratio range.

All mutations were screened in duplicate and positive controls consisting of DNA from heterozygous and homozygous individuals for FVL and MTHFR-C677T mutations, 
TABLE 1: Demographics of study cohort $(n=907)$ pregnant woment attending for antenatal care at UCH, Galway.

\begin{tabular}{|c|c|c|c|c|}
\hline \multicolumn{3}{|c|}{ Positive APCR } & \multicolumn{2}{|c|}{ Negative APCR } \\
\hline \multicolumn{5}{|c|}{ Distribution of parity by total population } \\
\hline Parity & Freq & $\%$ & Freq & $\%$ \\
\hline Primigravida & 59 & 42.2 & 301 & 40.3 \\
\hline Multigravida & 81 & 57.8 & 226 & 59.7 \\
\hline Data missing & 0 & 0 & 15 & 1.9 \\
\hline Total & 140 & 100 & 767 & 100 \\
\hline \multicolumn{5}{|c|}{ Distribution of maternal age by total population } \\
\hline Maternal age & Freq & $\%$ & Freq & $\%$ \\
\hline$<19$ & 12 & 8.6 & 38 & 5.1 \\
\hline $20-29$ & 29 & 20.7 & 143 & 19 \\
\hline 30-39 & 87 & 62.1 & 473 & 62.9 \\
\hline $40<45$ & 12 & 8.6 & 98 & 13 \\
\hline Data missing & 0 & 0 & 15 & 0 \\
\hline Total & 140 & 100 & 767 & 100 \\
\hline range & $15-42$ & & $16-45$ & \\
\hline mean & 28 & & 29 & \\
\hline \multicolumn{5}{|c|}{ Distribution of mode of delivery by total population } \\
\hline Mode of delivery & Freq & $\%$ & Freq & $\%$ \\
\hline Spontaneous vaginal delivery & 82 & 58.6 & 456 & 60.6 \\
\hline Assisted vaginal & 27 & 19.3 & 121 & 16.1 \\
\hline Cesarean Section & 29 & 20.7 & 158 & 21 \\
\hline Data missing & 2 & 1.4 & 32 & 2.3 \\
\hline Total & 140 & 100 & 767 & 100 \\
\hline \multicolumn{5}{|c|}{ Distribution of mode of delivery by total population } \\
\hline Mode of delivery & Freq & $\%$ & Freq & $\%$ \\
\hline SVD & 82 & 58.6 & 456 & 60.6 \\
\hline AV & 27 & 19.3 & 121 & 16.1 \\
\hline CS & 29 & 20.7 & 158 & 21 \\
\hline Data missing & 2 & 1.4 & 32 & 2.3 \\
\hline Total & 140 & 100 & 767 & 100 \\
\hline
\end{tabular}

SVD: Spontaneous vaginal delivery; AV: Assisted vaginal; CS: Cesarean section.

and heterozygous individuals for other mutations investigated were included where it was available. A negative control, consisting of water in place of DNA template, was included in each PCR run. PCR amplification was performed on the GeneAmp PCR System 9600 (Perkin Elmer, USA).

2.6. DNA Sequencing Verifying Mutations Identified. DNA sequencing on $50 \%$ of the PCR products from subjects screened for the $\operatorname{Arg}^{679}$ mutation was performed to verify the normal genotype obtained by Southern blot-DNA probe hybridisation analysis for these subjects. The $400 \mathrm{bp}$ PCR products from Exon 13 containing the Arg $^{679}$ site of the FV gene were purified using the QIAprep Spin Miniprep Kit (Qiagen Ltd, UK) according to the manufacturer's instructions and sent for DNA sequencing to an external sequence service provider (MWG Biotech, Germany). One sample positive for the Cambridge mutation by PCR/REA analysis was also purified using the QIAprep Spin Miniprep Kit (Qiagen Ltd, UK) and sent for sequencing to confirm the $\mathrm{Arg}^{306}$ mutation.
2.7. Levels of Factors V, VIII, and IX. Levels were determined for the APCR-positive and APCR-negative groups using a one-stage APTT assay on an MDA 180 coagulometer (Organon Teknika, Cambridge, UK), using factors V, VIII and IX deficient plasma's (Diagnostica Stago). The APCR negative group comprised of 50 women selected at random from different batch runs of Coatest tests providing the basis for the control group in comparing data between different variables.

Results for factors V, VIII, and IX levels were expressed as percentage (\%) levels, and the reference ranges used [30] are currently in clinical use at the Haematology Laboratory, UCHG. Each run was controlled by the use of a normal (MDA verify 1, Biomerieux) and abnormal control (coagulation control A, Technoclone $\mathrm{GmbH}$ ).

2.8. Statistical Analysis of Pregnancy Adverse Outcomes in the Group Observed in the 907 Women Included in the Study. Data was collected from the Maternity Department at UCHG. The number and type of pregnancy outcomes 
TABLE 2: Comparison of factor V, VII and IX in positive APCR acquired and inherited and negative APCR groups.

\begin{tabular}{|c|c|c|c|}
\hline \multicolumn{3}{|c|}{ Positive APCR } & \multirow[t]{2}{*}{ Negative APCR } \\
\hline \multicolumn{3}{|c|}{ Correlation between levels of the coagulation factor V and APCR } & \\
\hline Factor V levels & Acquired APCR & Inherited APCR & \\
\hline Number of values & 85 & 22 & 50 \\
\hline Minimum value & 89 & 110 & 88 \\
\hline Maximum value & 171 & 180 & 149 \\
\hline Mean & 131.5 & 131.7 & 114.6 \\
\hline Coefficient of variation & $13.35 \%$ & $12.34 \%$ & $13.49 \%$ \\
\hline \multicolumn{4}{|c|}{ Correlation between levels of the coagulation factor VIII and APCR } \\
\hline Factor VIII levels & Acquired APCR & Inherited APCR & \\
\hline Maximum value & 177 & 172 & 144 \\
\hline Minimum value & 73 & 90 & 91 \\
\hline Mean & 128.7 & 120.2 & 111.9 \\
\hline Coefficient of variation & $16.79 \%$ & $18.10 \%$ & $12.14 \%$ \\
\hline \multicolumn{4}{|c|}{ Correlation between levels of the coagulation factor IX and APCR } \\
\hline Factor IX levels & Acquired APCR & Inherited APCR & \\
\hline Number of values & 85 & 22 & 50 \\
\hline Minimum value & 90 & 85 & 89 \\
\hline Maximum value & 167 & 169 & 125 \\
\hline Mean & 114.8 & 114.2 & 106.9 \\
\hline Coefficient of variation & $11.93 \%$ & $16.25 \%$ & $8.53 \%$ \\
\hline
\end{tabular}

studied were analysed using SPSS version 17.0 software. The Pearson Chi Square test was used to compare the APCRpositive group and the negative APCR group to analyze the thrombophilic mutations and the range of adverse outcomes associated with each group. The Pearson Chi-Square test was used to compare the number and type of adverse pregnancy outcomes in the inherited versus acquired APCR group. SPSS was used to analyse the levels of coagulation factors V, VIII, and IX using Kruskal-Wallis statistical testing.

2.9. Criteria for Adverse Outcomes Diagnosis. PET-BP (Blood pressure) $\geq 140 / 90 \mathrm{mmHg},+1$ proteinuria and oedema. $\mathrm{PIH}-$ $\mathrm{BP} \geq 140 / 90$ with no proteinuria in accordance with the Official Journal of the International Society for the Study of Hypertension in Pregnancy. IUGR is defined as fetal growth of less than 5th percentile for gestational age [25]. LBW is defined as a weight of less than $2500 \mathrm{~g}$ (up to and including $2499 \mathrm{~g}$ ), irrespective of gestational age.

\section{Results}

We identified $15.4 \%(n=140)$ of the study cohort $(n=907)$ as APCR positive with acquired and/or inherited Coatest tests. Factors V, VIII, and IX levels showed a positive correlation with an acquired APCR phenotype. The levels for each factor in the APCR positive (inherited) and APCRpositive (acquired) and APCR-negative groups are shown in Table 2 and Figure 1. Levels of factors V, VIII, and IX in the acquired APCR group were significantly higher compared to the normal control group. The means were factor $\mathrm{V}$ 131.5 IU/dL versus 114.6 IU/dL for the control group, factor
VIII 128.7 IU/dL versus $111.9 \mathrm{IU} / \mathrm{dL}$ in the control group and factor IX $114.8 \mathrm{IU} / \mathrm{dL}$ versus $106.9 \mathrm{IU} / \mathrm{dL}$ in the control group.

Ninety-two subjects (66\%) of the positive APCR group had common thrombophilic mutations, $32 \%$ of whom had the FVL mutation. A total of $n=116$ mutations were identified in this group, 68 subjects had one mutation, 23 had two mutations, 1 subject had three mutations, and fortyeight subjects did not have any of the known mutations screened for.

Within the acquired (without FVL) positive APCR ( $n=$ 105), 70 mutations were distributed among 61 subjects who had one or more of these mutations. Within the negative APCR group $(n=31), 18$ subjects had one mutation. The distribution of thrombophilic mutations is summarised in Table 3.

Frequencies of adverse outcomes in positive APCR and negative APCR groups were very similar at $35.7 \%$ and $34.2 \%$, respectively (Table 4 ). The comparison of adverse pregnancy outcomes and thrombophilic mutations is summarised in Table 5. PIH showed statistical significant $(P<0.05)$ association with Cambridge and prothrombin G20210A. LBW showed statistical significant $(P<0.05)$ association with HR2 and MTHFR.

\section{Discussion}

The frequency of APCR has been reported as approximately $5 \%$ in the general Caucasian population $[31,32]$. This varies from $1 \%$ to $15 \%$ in different countries with a frequency of $3 \%$ reported in Italy and Spain and a frequency of 
TABLE 3: Distribution of the thrombophilic mutations identified in our study cohort.

\begin{tabular}{|c|c|c|c|c|}
\hline APC & $\begin{array}{c}\text { Mutations } \\
\text { identified/subjects tested }\end{array}$ & $\begin{array}{l}\text { Frequency from the subset of } \\
\text { subjects tested in each group } \\
\left(*^{*} 1\right)\left(*^{*} 2\right),\left(*^{*}\right) .\end{array}$ & $\begin{array}{l}\text { Frequency from the } \\
\text { total cohort } n=907\end{array}$ & $\begin{array}{c}\text { Thrombophilic mutations } \\
\text { identified }\end{array}$ \\
\hline \multirow[t]{7}{*}{$\left({ }^{*} 1\right) n=140$} & $\begin{array}{c}\text { Positive APCR } \\
\text { (inherited and acquired) }\end{array}$ & & & \\
\hline & $67 / 140$ & $47.8 \%$ & $7.3 \%$ & $\begin{array}{l}\text { MTHFR-C677T } \\
(54 \mathrm{ht} 13 \mathrm{hom})\end{array}$ \\
\hline & $3 / 140$ & $2.1 \%$ & $0.3 \%$ & ht prothrombin G20210A \\
\hline & $16 / 140$ & $11.4 \%$ & $1.7 \%$ & ht $(\mathrm{H}) \mathrm{R} 2$ \\
\hline & $29 / 140$ & $20.7 \%$ & $3.1 \%$ & ht FV Leiden \\
\hline & $1 / 140$ & $0.7 \%$ & $0.1 \%$ & ht Cambridge \\
\hline & $48 / 140$ & $31.4 \%$ & $3.9 \%$ & no mutation \\
\hline \multirow[t]{5}{*}{$(* 2) n=105$} & Positive APCR (acquired) & & & \\
\hline & $51 / 105$ & $48.5 \%$ & $5.6 \%$ & $\begin{array}{l}\text { MTHFR -C677T } \\
\text { (38ht13hom) }\end{array}$ \\
\hline & $3 / 105$ & $2.8 \%$ & $0.3 \%$ & ht Prothrombin G20210A \\
\hline & $16 / 105$ & $15.2 \%$ & $1.7 \%$ & $h t(H) R 2$ \\
\hline & $44 / 105$ & $41.9 \%$ & $4.8 \%$ & no mutations \\
\hline \multirow[t]{4}{*}{$(* 3) n=31$} & Negative APCR & & & \\
\hline & $5 / 31$ & $16.1 \%$ & $0.6 \%$ & ht (H) R2 \\
\hline & $13 / 31$ & $41.9 \%$ & $1.7 \%$ & MTHFR-C677T \\
\hline & $13 / 31$ & $41.9 \%$ & $1.7 \%$ & No mutation \\
\hline
\end{tabular}

(*1) $n=140$ are subjects with total APCR (acquired +modified).

(*2) $n=105$ are subjects with acquired APCR, without inherited FVL.

(*3) $n=31$ are negative APCR subjects tested out of 767 .

$n$ : Number of subjects; ht: Heterozygotes; hom: Homozygotes; H: Haplotype.

Subjects identified with more than one mutation simultaneously:

in the total APCR group, (inherited plus acquired) They had 13 subjects with MTHFR+FVL; 1subject with MTHFR + FVL + Cambridge; 7 subjects with MTHFR + HR2; 1 subject with prothrombin G20210A + HR2; and 1 subject with prothrombin G20210A + MTHFR; in the acquired APCR group, They had 7 subjects with MTHFR+HR2; 1 subject with prothrombin G20210A + HR2; 1 subject with prothrombin G20210A + MTHFR.

TABle 4: Frequency of adverse outcomes identified in positive APCR (acquired plus inherited) versus negative APCR. $P$ value from Pearson Chi-Square test applied to positive APCR (acquired plus inherited) versus negative APCR.

\begin{tabular}{|c|c|c|c|c|c|c|c|c|}
\hline & & $\begin{array}{c}\text { Total outcomes } \\
\text { frequency }\end{array}$ & EPL & PET & $\mathrm{PIH}$ & IUGR & IUFD & LBW \\
\hline Positive & $N=140$ & $N=50$ & $N=38$ & $N=3$ & $N=12$ & $N=1$ & $N=0$ & $N=37$ \\
\hline APCR & Freq.\% & $35.7 \%$ & $27.1 \%$ & $2.2 \%$ & $8.6 \%$ & $0.7 \%$ & $0 \%$ & $26.8 \%$ \\
\hline Negative & $N=767$ & $N=262$ & $N=196$ & $N=39$ & $N=37$ & $N=20$ & $N=3$ & $N=256$ \\
\hline APCR & Freq.\% & $34.2 \%$ & $25.7 \%$ & $5.2 \%$ & $4.9 \%$ & $2.6 \%$ & $0.4 \%$ & $34.5 \%$ \\
\hline $\begin{array}{l}\text { Pearson } \\
\text { Chi-Square }\end{array}$ & $P$ value & 0.722 & 0.712 & 0.125 & 0.077 & 0.168 & 0.456 & 0.080 \\
\hline
\end{tabular}

Table 5: Results from Pearson Chi-Square test. $P$ values for the association between each adverse pregnancy outcome identified in this study and thrombophilic mutations indentified in our total study cohort $n=907$.

\begin{tabular}{lccccccc}
\hline$P$ values & Presence of outcomes & EPL & PET & PIH & IUGR & IUFD & LBW \\
\hline FVL & 0.237 & 0.832 & 0.748 & $\mathbf{0 . 0 0 4}$ & 0.396 & 0.751 & 0.289 \\
Cambridge & 0.469 & 0.554 & 0.822 & $\mathbf{0 . 0 0 0}$ & 0.877 & 0.954 & 0.480 \\
HR2 & 0.951 & 0.654 & 0.194 & 0.466 & N/A & N/A & $\mathbf{0 . 0 1 6}$ \\
Prothrombin & 0.426 & 0.133 & 0.928 & $\mathbf{0 . 0 0 8}$ & 0.413 & 0.883 & 0.907 \\
MTHFR & 0.859 & 0.203 & 0.428 & 0.584 & N/A & N/A & $\mathbf{0 . 0 4 8}$ \\
\hline
\end{tabular}

NA: no statistics are computed because there is no IUGR in the MTHFR and HR2 groups. 
Factor V data

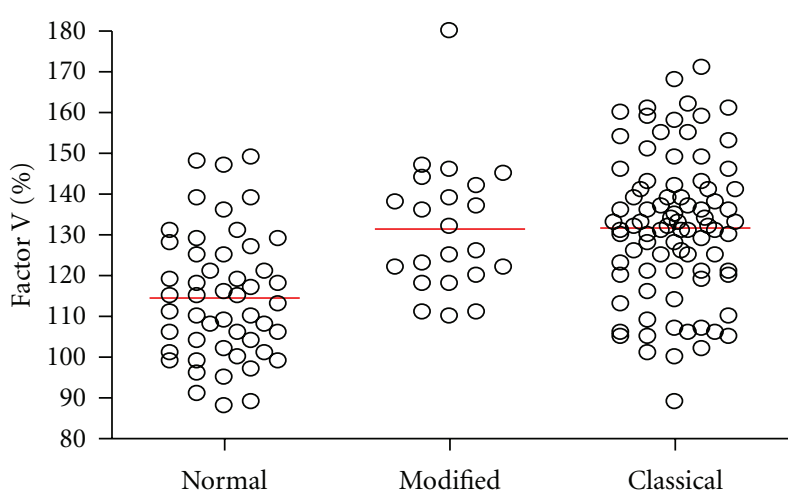

Kruskal-Wallis test for levels of FV

$P$ value

Exact or approximate $P$ value?

Do the means vary significantly

Number of groups

Kruskal-Wallis statistic

$P<0.0001$

Gaussian approximation

$(P<0.05) \quad$ Yes

3

30.26

(a)

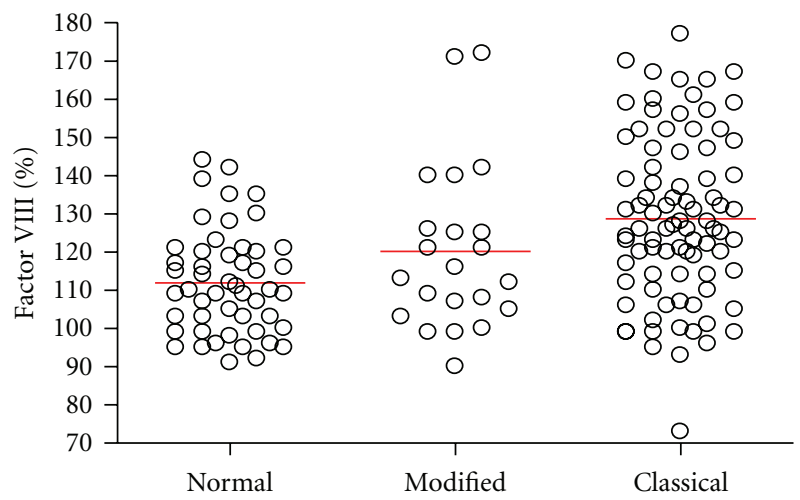

\section{Kruskal-Wallis test for levels of FVIII}

$P$ value

Exact or approximate $P$ value?

$P<0.0001$

Do the means vary significantly

Number of groups

Kruskal-Wallis statistic

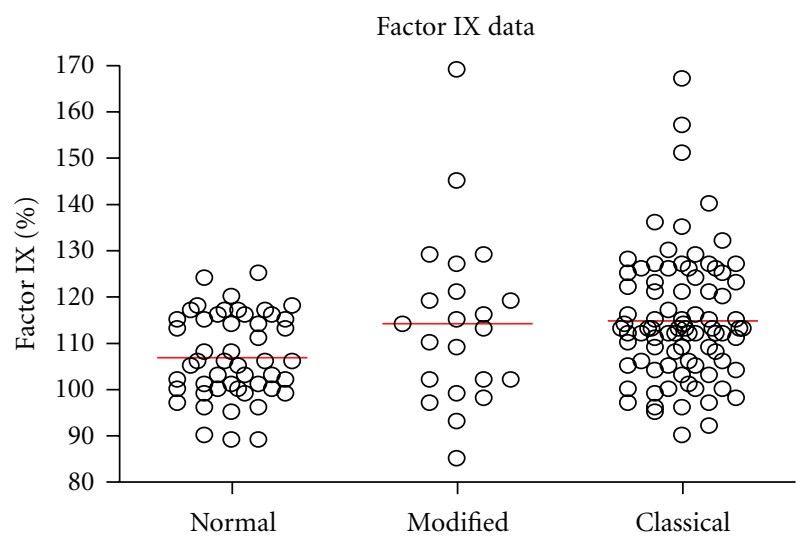

Kruskal-Wallis test for levels of FIX

$P$ value

Exact or approximate $P$ value?

Do the means vary significantly

Number of groups

Kruskal-Wallis statistic
0.0092

Gaussian approximation

$(P<0.05) \quad$ Yes

3

9.378

(c)

FIGURE 1: (a) Graph comparing FV levels in differing groups within the study, (b) graph comparing FVIII levels in differing groups within the study, and (c) graph comparing F IX levels in differing groups within the study.

15\% reported in Northern Sweden [33]. APCR in the general population and during pregnancy is reported to be most frequently caused by FVL mutation [34-36], inherited APCR.

Several reports have shown, however, that between 5 and $10 \%$ of APCR in Caucasians does not involve the FVL, and the cause of positive APCR in these cases is not known [34, 37-40]. In our study cohort $(n=907)$, the frequency of acquired APCR, determined by the classic Coatest test method, of $11.5 \%$, was substantially higher than the frequency of inherited APCR identified by modified Coatest tests, 3.9\%. De Visser et al. demonstrated that an 
altered APCR in the absence of FVL confers a 2.5 -fold increased risk for venous thrombosis [41].

In this study, a significant statistical correlation of the acquired APCR phenotype with Factors V, VIII, and IX levels was demonstrated. Further study would be required to determine the interaction of coagulation factors to further characterize this acquired APCR phenotype in early pregnancy. Acquired APCR can be the result of a complex series of reactions giving a defective APC-mediated degradation of these coagulation factors. In turn, an increase of these coagulation factors in early pregnancy stages could cause an imbalance in the coagulation cascade and lead to vascular and endothelial damage during implantation and placentation. This has the potential to cause placental infarcts and high levels of fibrin deposition, which has been previously associated with APCR [42]. Spontaneous abortion may take place in response to an increased coagulation imbalance, and if there are other thrombotic factors including thrombophilic mutations interacting simultaneously when the subject is beyond the 20th week of pregnancy, the damage could develop into PET or PIH.

Mutations in the FV gene excluding FVL, particularly at the other cleavage sites of $\mathrm{FV}, \mathrm{Arg}^{306}$, and $\mathrm{Arg}^{679}$, have the potential to contribute to the APCR phenotype $[6,43]$. Haplotype (H) R2 has also been associated with mild APCR when found in combination with the FVL $[7,10,44,45]$. There have been a number of other mutations identified in the FV gen; however, a larger pregnant population would need to be studied to determine if these mutations contribute significantly to APCR in the Caucasian populations [21, 4648]. Thrombophilia during pregnancy has been linked with mutations other than those located in the FV gene including prothrombin G20210A and MTHFR-C677T [17, 49, 50]. In this study, we identified thrombophilic mutations in $66 \%$ of our positive APCR (acquired plus inherited) group ( $n=$ 140). One of those subjects had 2 mutations in the FV gene, FVL and FV Cambridge-G1091C, at two cleavages sites of FV for APC [21]. This subject was also found in this study to be a carrier of MTHFR-C677T mutation. Previous studies established that the presence of more than one prothrombotic polymorphism is associated with a substantial risk of VTE with a high risk of adverse pregnancy outcomes [51, 52]. In addition, more recently MTHFR-C677T mutation has been implicated in pre-eclampsia. The high frequency of MTHFRC677T in the negative APCR and positive APCR groups may underlie populations-specific differences [53]. Discrepancies in the adverse pregnancy outcomes associated with MTHFRC677T may be explained by the specific frequency differences among populations $[54,55]$.

We also identified prothrombin G20210A in 3 subjects in the acquired APCR group without the presence of FVL mutation, with the (H) HR2 haplotype and MTHFR-C677T identified in both positive APCR (acquired plus inherited) and negative APCR groups.

The negative APCR samples $(n=31)$ tested for thrombophilic mutations in this study to represent the normal cohort are a small sample number, and this may be a flaw in our study resulting in nonsignificant differences. Testing a larger number of negative APCR would have given more confident results. This can be something to be investigated in a future study.

While some previous studies have shown an association of positive APCR with PET, IUGR, and IUFD [55] in this study there was no significant difference in the frequency of adverse outcomes between positive APCR and negative APCR groups. This seems to be consistent with other previous studies [56]. Nonetheless, the overall frequency adverse pregnancy outcomes in the positive APCR makes this study group "a high-risk group." Environmental factors such as smoking and body mass index (BMI) that could have influenced the rate of acquired APCR and the frequency of adverse outcomes identified, were not included. This is a limitation of the study.

In our total study group, thrombophilic mutations including FVL Cambridge and Prothrombin G20210A seem to be related to PIH, whereas MTHFR-C677T and HR2 haplotype appeared to be associated with LBW. Although positive APCR by itself does not seem to be the cause of severe adverse outcomes during pregnancy, inherited APCR can nevertheless have an effect on hypertension when it is present in combination with other known and unknown thrombophilic risk factors acting simultaneously during pregnancy.

\section{Acknowledgments}

This work was supported by the Irish Health Research Board. The authors gratefully acknowledge the pregnant women who consented to be involved in the study and the midwives from the labour ward at the UCHG. The authors wish to acknowledge Benoit Houeix for his input on the statistical analysis included in this paper and also to Dr. D. Mongan, UCH, Galway, for her cooperation on providing the information on adverse outcomes and data analysis of the subjects included in the study.

\section{References}

[1] "Report on confidential enquiries into maternal deaths," in Reports on Public Health and Medical Subjects 1994-1996, L. Gwyneth, Ed., Department of Health United Kingdom, London, UK, 1998.

[2] S. C. M. Knijff, Ed., Summary of Contraindications to Oral Contraceptives, Parthenon Publishing Group, New York, NY, USA, 2000.

[3] I. Martinelli, "Risk factors in venous thromboembolism," Thromb Haemost, vol. 86, pp. 395-403, 2001.

[4] M. Kalafatis, R. M. Bertina, M. D. Rand, and K. G. Mann, "Characterization of the molecular defect in factor V(R506Q)," Journal of Biological Chemistry, vol. 270, no. 8, pp. 4053-4057, 1995.

[5] F. Axelsson and S. Rosen, APC Resistance, Product Monograph 1997, Chromogenix AB, version 2.11997.

[6] D. Williamson, K. Brown, R. Luddington, C. Baglin, and T. Baglin, "Factor V cambridge: a new mutation (Arg306 $\rightarrow$ Thr) associated with resistance to activated protein C," Blood, vol. 91, no. 4, pp. 1140-1144, 1998.

[7] F. Bernardi, E. M. Faioni, E. Castoldi et al., "A factor V genetic component differing from factor V R506Q contributes to the 
activated protein C resistance phenotype," Blood, vol. 90, no. 4, pp. 1552-1557, 1997.

[8] B. Zoller, P. J. Svensson, X. He, and B. Dahlback, "Identification of the same factor $\mathrm{V}$ gene mutation in 47 out of 50 thrombosis-prone families with inherited resistance to activated protein C," Journal of Clinical Investigation, vol. 94, no. 6, pp. 2521-2524, 1994.

[9] M. Kalafatis, M. D. Rand, and K. G. Mann, "The mechanism of inactivation of human factor $\mathrm{V}$ and human factor $\mathrm{Va}$ by activated protein C," Journal of Biological Chemistry, vol. 269, no. 50, pp. 31869-31880, 1994.

[10] L. Hoekema, E. Castoldi, G. Tans et al., "Functional properties of factor $\mathrm{V}$ and factor Va encoded by the R2-gene," Thrombosis and Haemostasis, vol. 85, no. 1, pp. 75-81, 2001.

[11] M. Hellgren, P. J. Svensson, and B. Dahlback, "Resistance to activated protein $\mathrm{C}$ as a basis for venous thromboembolism associated with pregnancy and oral contraceptives," American Journal of Obstetrics \& Gynecology, vol. 173, pp. 210-210, 1995.

[12] A. M. Cumming, R. C. Tait, S. Fildes, A. Yoong, S. Keeney, and C. R. M. Hay, "Development of resistance to activated protein C during pregnancy," British Journal of Haematology, vol. 90, no. 3, pp. 725-727, 1995.

[13] M. Colucci, N. Ciavarella, M. G. Giliberti, and N. Semeraro, "Resistance to activated protein C (APC): influence of factor V levels," Thrombosis and Haemostasis, vol. 72, no. 6, pp. 987988, 1994.

[14] G. Freyburger, S. Javorschi, S. Labrouche, and P. Bernard, "Proposal for objective evaluation of the performance of various functional APC-resistance tests in genotyped patients," Thrombosis and Haemostasis, vol. 78, no. 5, pp. 1360-1365, 1997.

[15] M. R. Malinow, A. Rajkovic, P. B. Duell, D. L. Hess, and B. M. Upson, "The relationship between maternal and neonatal umbilical cord plasma homocyst(e)ine suggests a potential role for maternal homocyst(e)ine in fetal metabolism," American Journal of Obstetrics \& Gynecology, vol. 178, no. 2, pp. 228233, 1998.

[16] M. J. Kupferminc, A. Eldor, N. Steinman et al., "Increased frequency of genetic thrombophilia in women with complications of pregnancy," The New England Journal of Medicine, vol. 340, no. 1, pp. 9-13, 1999.

[17] V. Dordevic, L. Rakicevic, M. Spasic, D. Mikovic, M. Kovac, and D. Radojkovic, "Factor V Leiden, FII G20210A, MTHFR C677T mutations as risk factors for venous thrombosis during pregnancy and puerperium," Vojnosanit Pregl, vol. 62, pp. 201205, 2005.

[18] E. Grandone, M. Margaglione, D. Colaizzo, G. Cappucci et al., "Prothrombotic genetic risk factors and the occurrence of gestational hypertension with or without proteinuria," Thrombosis and Haemostasis, vol. 81, pp. 349-352, 1999.

[19] K. D. Wenstrom, G. L. Johanning, K. E. Johnston, and M. DuBard, "Association of the C677T methylenetetrahydrofolate reductase mutation and elevated homocysteine levels with congenital cardiac malformations," American Journal of Obstetrics \& Gynecology, vol. 184, pp. 806-812, 2001.

[20] G. Unfried, A. Griesmacher, W. Weismuller, F. Nagele, J. C. Huber, and C. B. Tempfer, "The C677T polymorphism of the methylenetetrahydrofolate reductase gene and idiopathic recurrent miscarriage," Obstetrics \& Gynecology, vol. 99, pp. 614-619, 2002.

[21] S. Sedano-Balbás, M. Lyons, B. Cleary, M. Murray, G. Gaffney, and M. Maher, "APCR, factor $\mathrm{V}$ gene known and novel SNPs and adverse pregnancy outcomes in an Irish cohort of pregnant women," BMC Pregnancy and Childbirth, vol. 10, article 11, 2010.

[22] M. C. Walker, P. R. Garner, E. J. Keely, G. A. Rock, and M. D. Reis, "Changes in activated protein $\mathrm{C}$ resistance during normal pregnancy," American Journal of Obstetrics \& Gynecology, vol. 177, no. 1, pp. 162-169, 1997.

[23] M. Trossaert, J. Conard, M. H. Horellou et al., "Modified APC resistance assay for patients on oral anticoagulants," The Lancet, vol. 344, no. 8938, p. 1709, 1994.

[24] J. I. Jorquere, J. M. Montoro, M. A. Fernandez, J. A. Aznar, and J. Aznar, "Modified test for activated protein C resistance," The Lancet, vol. 344, no. 8930, pp. 1162-1163, 1994.

[25] P. M. Ridker, C. H. Hennekens, K. Lindpaintner, M. J. Stampfer, P. R. Eisenberg, and J. P. Miletich, "Mutation in the gene coding for coagulation factor $\mathrm{v}$ and the risk of myocardial infarction, stroke, and venous thrombosis in apparently healthy men," The New England Journal of Medicine, vol. 332, no. 14, pp. 912-917, 1995.

[26] B. Lunghi, L. Iacoviello, D. Gemmati et al., "Detection of new polymorphic markers in the factor $\mathrm{V}$ gene: association with factor V levels in plasma," Thrombosis and Haemostasis, vol. 75, no. 1, pp. 45-48, 1996.

[27] B. Lunghi, E. Castoldi, F. Mingozzi, and F. Bernardi, "A new factor $\mathrm{V}$ gene polymorphism (His 1254 Arg) present in subjects of african origin mimics the R2 polymorphism (His 1299 Arg)," Blood, vol. 91, no. 1, pp. 364-365, 1998.

[28] S. R. Poort, F. R. Rosendaal, P. H. Reitsma, and R. M. Bertina, "A common genetic variation in the 3 '-untranslated region of the prothrombin gene is associated with elevated plasma prothrombin levels and an increase in venous thrombosis," Blood, vol. 88, no. 10, pp. 3698-3703, 1996.

[29] F. Peng, L. A. Labelle, B. J. Rainey, and G. J. Tsongalis, "Single nucleotide polymorphisms in the methylenetetrahydrofolate reductase gene are common in US Caucasian and Hispanic American populations," International Journal of Molecular Medicine, vol. 8, no. 5, pp. 509-511, 2001.

[30] M. D. Williams, E. A. Chalmers, and B. E. S. Gibson, "The investigation and management of neonatal haemostasis and thrombosis," British Journal of Haematology, vol. 119, no. 2, pp. 295-309, 2002.

[31] J. P. Gregg, A. J. Yamane, and W. W. Grody, "Prevalence of the factor V-Leiden mutation in four distinct American ethnic populations," American Journal of Medical Genetics, vol. 73, no. 3, pp. 334-336, 1997.

[32] A. Naudziunas and S. Miliauskas, "Factor V Leiden and post thromboembolic pulmonary hypertension," Medicina, vol. 39, no. 12, pp. 1171-1174, 2003.

[33] B. Dahlbäck, B. Zöller, and A. Hillarp, "Inherited resistance to activated protein $\mathrm{C}$ caused by presence of the FV:Q506 allele as a basis of venous thrombosis," Haemostasis, vol. 26, no. 4, pp. 301-314, 1996.

[34] R. M. Bertina, B. P. C. Koeleman, T. Koster et al., "Mutation in blood coagulation factor $\mathrm{V}$ associated with resistance to activated protein C," Nature, vol. 369, no. 6475, pp. 64-67, 1994.

[35] B. Dahlback and B. Hildebrand, "Inherited resistance to activated protein $\mathrm{C}$ is corrected by anticoagulant cofactor activity found to be a property of factor V," Proceedings of the National Academy of Sciences of the United States of America, vol. 91, no. 4, pp. 1396-1400, 1994.

[36] X. Sun, B. Evatt, and J. H. Griffin, "Blood coagulation factor Va abnormality associated with resistance to activated protein C in venous thrombophilia," Blood, vol. 83, no. 11, pp. 3120$3125,1994$. 
[37] B. Zoller and B. Dahlback, "Linkage between inherited resistance to activated protein $\mathrm{C}$ and factor $\mathrm{V}$ gene mutation in venous thrombosis," The Lancet, vol. 343, no. 8912, pp. 1536$1538,1994$.

[38] J. H. Griffin, M. J. Heeb, Y. Kojima et al., "Activated protein C resistance: molecular mechanisms," Thrombosis and Haemostasis, vol. 74, no. 1, pp. 444-448, 1995.

[39] R. M. Bertina, P. H. Reitsma, F. R. Rosendaal, and J. P. Vandenbroucke, "Resistance to activated protein $\mathrm{C}$ and factor V Leiden as risk factors for venous thrombosis," Thrombosis and Haemostasis, vol. 74, no. 1, pp. 449-453, 1995.

[40] G. Siegert, S. Gehrish, S. Schellong, T. Schwarz, E. Runge, and K. Lüthke, "Decreased APC-response in patients lacking factor V-Leiden-Laboratory diagnostic and clinical relevance," Thromb Haemost, pp. 317-318, 1997.

[41] M. C. H. de Visser, F. R. Rosendaal, and R. M. Bertina, "A reduced sensitivity for activated protein $C$ in the absence of factor V Leiden increases the risk of venous thrombosis," Blood, vol. 93, no. 4, pp. 1271-1276, 1999.

[42] S. Sedano, G. Gaffney, G. Mortimer et al., "Activated Protein C Resistance (APCR) and Placental Fibrin Deposition," Placenta, vol. 29, no. 9, pp. 833-837, 2008.

[43] L. C. Chan, C. Bourke, C. K. Lam et al., "Lack of activated protein $\mathrm{C}$ resistance in healthy Hong Kong Chinese blood donors - correlation with absence of Arg506-Gln mutation of factor V gene," Thrombosis and Haemostasis, vol. 75, no. 3, pp. 522-523, 1996.

[44] R. Luddington, A. Jackson, S. Pannerselvam, K. Brown, and T. Baglin, "The factor V R2 allele: risk of venous thromboembolism, factor $\mathrm{V}$ levels and resistance to activated protein C," Thrombosis and Haemostasis, vol. 83, no. 2, pp. 204-208, 2000.

[45] G. Castaman, M. Ruggeri, A. Tosetto, and F. Rodeghiero, "Heterogeneity of activated protein $\mathrm{C}$ resistance phenotype in subjects with compound heterozygosity for HR2 haplotype and FV Leiden mutation (R506Q) in factor V gene," Thrombosis and Haemostasis, vol. 84, no. 2, pp. 357-358, 2000.

[46] S. Gandrille, J. S. Greengard, M. Alhenc-Gelas et al., "Incidence of activated protein $C$ resistance caused by the ARG 506 GLN mutation in factor V in 113 unrelated symptomatic protein C-deficient patients. The French Network on the behalf of INSERM," Blood, vol. 86, pp. 219-224, 1995.

[47] W. P. Chan, C. K. Lee, Y. L. Kwong, C. K. Lam, and R. Liang, "A novel mutation of Arg306 of factor V gene in Hong Kong Chinese," Blood, vol. 91, no. 4, pp. 1135-1139, 1998.

[48] M. C. De Visser, J. F. Guasch, P. W. Kamphuisen, H. L. Vos, F. R. Rosendaal, and R. M. Bertina, "The HR2 haplotype of factor V: effects on factor V levels, normalised activated protein $\mathrm{C}$ sensitivity ratios and the risk of venous thrombosis," Thrombosis and Haemostasis, vol. 83, pp. 577-582, 2000.

[49] G. Sarig, J. S. Younis, R. Hoffman, N. Lanir, Z. Blumenfeld, and B. Brenner, "Thrombophilia is common in women with idiopathic pregnancy loss and is associated with late pregnancy wastage," Fertility and Sterility, vol. 77, no. 2, pp. 342-347, 2002.

[50] M. Prochazka, V. Krcova, P. Hrachovec, M. Kudela, and L. Slavik, "Activated protein C resistance and deep venous thrombosis in pregnancy," Ceska Gynekol, vol. 67, pp. 251-254, 2002.

[51] A. Santamaria, J. M. Soria, I. Tirado et al., "Double heterozygosity for Factor V Leiden and Factor V Cambridge mutations associated with low levels of activated protein $\mathrm{C}$ resistance in a Spanish thrombophilic family," Thrombosis and Haemostasis, vol. 93, pp. 1193-1195, 2005.
[52] O. Salomon, D. M. Steinberg, A. Zivelin et al., "Single and combined prothrombotic factors in patients with idiopathic venous thromboembolism: prevalence and risk assessment," Arteriosclerosis, Thrombosis, and Vascular Biology, vol. 19, no. 3, pp. 511-518, 1999.

[53] S. Sohda, T. Arinami, H. Hamada, N. Yamada, H. Hamaguchi, and T. Kubo, "Methylenetetrahydrofolate reductase polymorphism and pre-eclampsia," Journal of Medical Genetics, vol. 34, no. 6, pp. 525-526, 1997.

[54] M. J. Hessner, R. A. Luhm, S. L. Pearson, D. J. Endean, K. D. Friedman, and R. R. Montgomery, "Prevalence of prothrombin G20210A, factor V G1691A (Leiden), and methylenetetrahydrofolate reductase (MTHFR) C677T in seven different populations determined by multiplex allele-specific PCR," Thrombosis and Haemostasis, vol. 81, no. 5, pp. 733-738, 1999.

[55] J. L. Kujovich, "Thrombophilia and pregnancy complications," American Journal of Obstetrics \& Gynecology, vol. 191, no. 2, pp. 412-424, 2004.

[56] L. Robertson, O. Wu, P. Langhorne et al., "Thrombophilia in pregnancy: a systematic review," British Journal of Haematology, vol. 132, no. 2, pp. 171-196, 2006. 


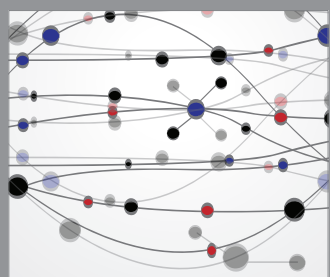

The Scientific World Journal
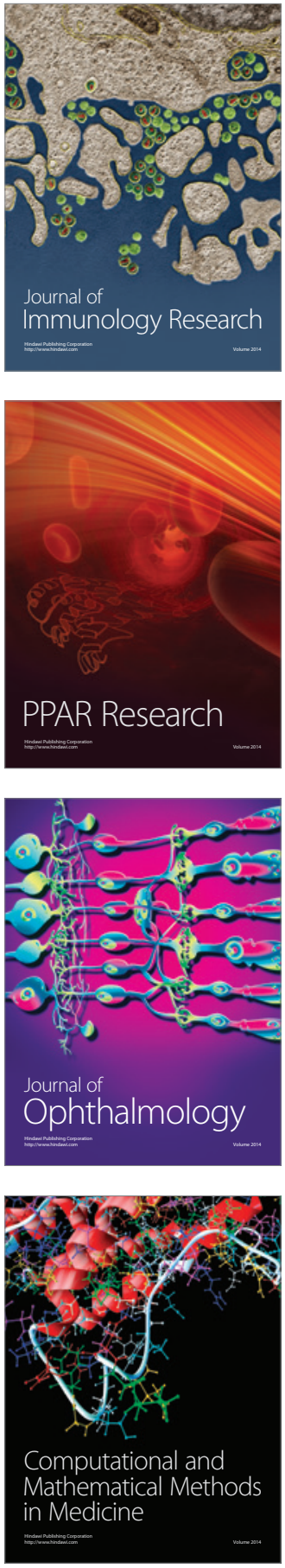

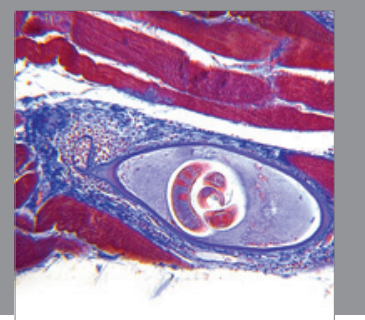

Gastroenterology

Research and Practice
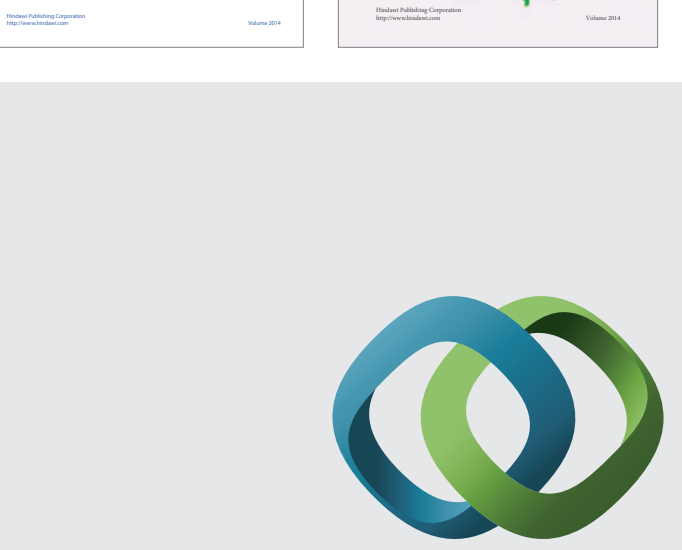

\section{Hindawi}

Submit your manuscripts at

http://www.hindawi.com
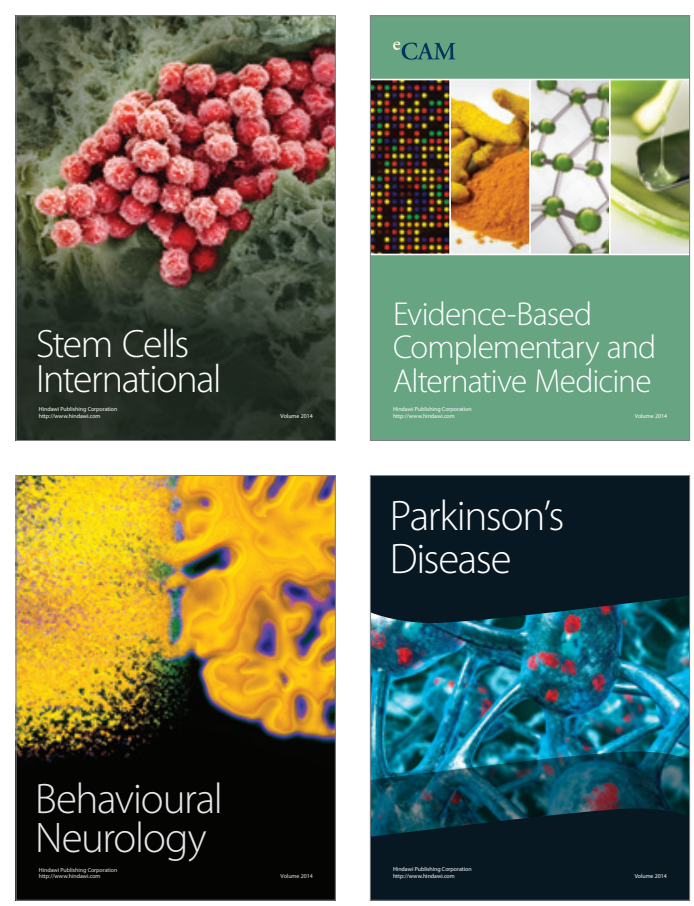

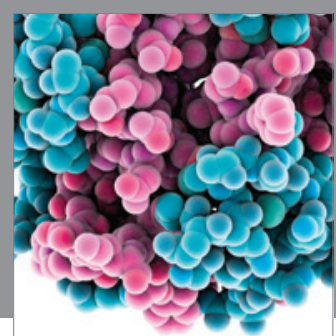

Journal of
Diabetes Research

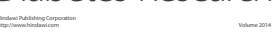

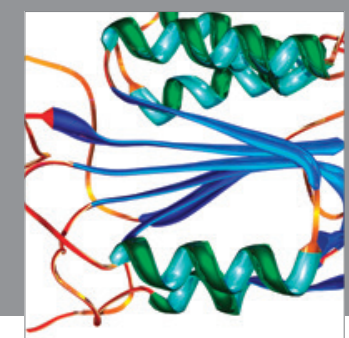

Disease Markers
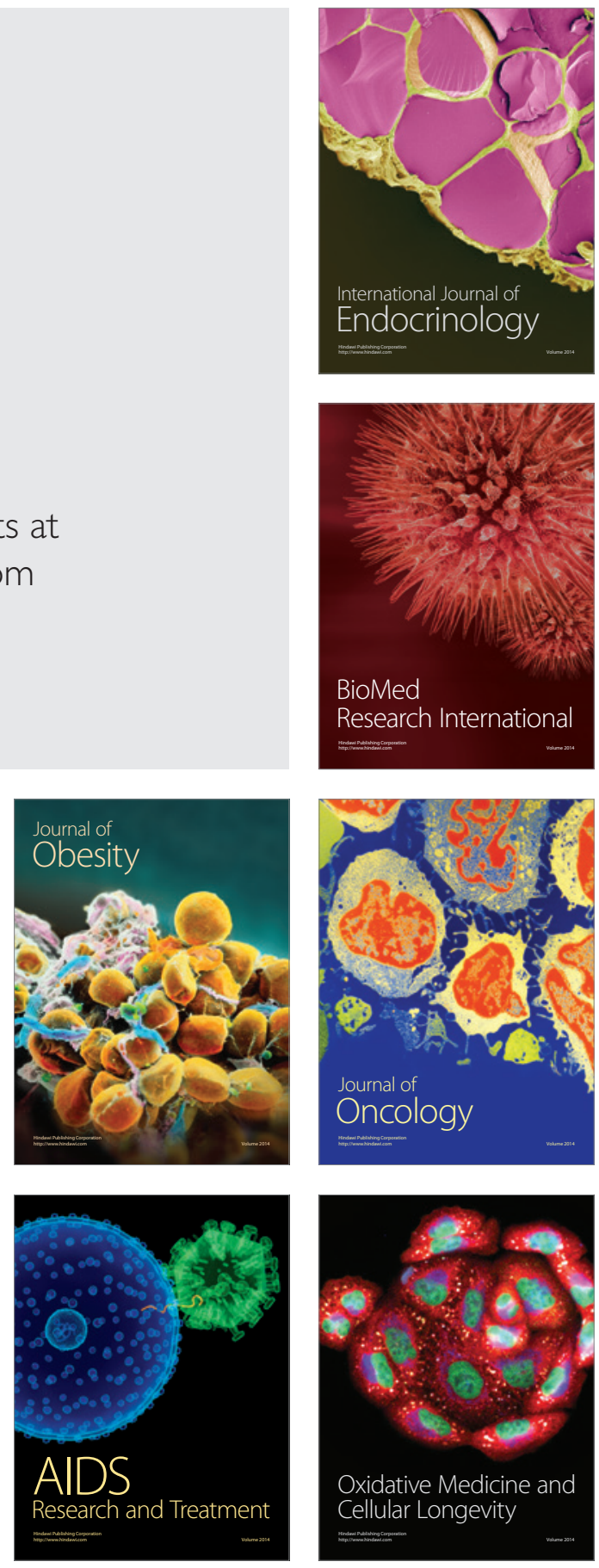